síveis, potentes, jovens, produtivos, flexíveis etc. Nesse sentido, parecem estar desaparecendo rapidamente os antigos pudores que, fazendo da atenção sobre si ou sobre o próprio corpo um sinal de feminilidade, tinham como um de seus mais importantes efeitos manter os homens distantes dos médicos e da medicina. E se isso tem se tornado possível, talvez seja, como queria Boltanski porque a força física (símbolo mais básico ou mais primitivo da masculinidade) venha tendo um papel cada vez menos relevante do ponto de vista de um processo produtivo cada vez mais automatizado e informatizado.

Além disso, a emergência dos homens na qualidade de consumidores de bens voltados à sua masculinidade parece estar também na dependência das profundas alterações a que assistimos nas próprias estruturas familiares. Homens não-casados, vivendo sozinhos ou em arranjos familiares não-convencionais são cada vez menos intensamente considerados casos escandalosos de anomalia social e/ou sexual. Isso parece querer dizer que um número crescente de homens está destinado a consumir para e por suas famílias, não mais o fazendo através das mulheres. Assim a identidade de pai ou de chefe de família cede o passo à genérica identidade social de homem, base sobre a qual todo o novo mercado se organiza.

Paralelamente a isso, temos inúmeros sinais de corrosão da dominação masculina que se expressam na esfera propriamente política. Concentro-me aqui em dois temas que, como ressaltam os autores, se vinculam privilegiadamente à construção dos homens como objeto de reflexão na área da Saúde Coletiva: a violência e a sexualidade. Se esses temas são privilegiados no campo científico isso se explica também pelo fato de haver investimentos estatais importantes no sentido de limitar e colocar sob vigilância cerrada tradicionais prerrogativas masculinas dentro e fora da família. Toda a atual discussão em torno da violência doméstica, do abuso sexual de crianças ou da violência contra homossexuais, com o conseqüente aparecimento de leis e instituições destinadas a mais eficazmente coibir tais práticas (como é o caso das delegacias especiais da mulher no Brasil), parece ter como objetivo o controle mais estrito do comportamento masculino ou, ao menos, o combate a certas expressões tradicionais de masculinidade. Também as políticas de controle às doenças sexualmente transmissíveis, e em especial à Aids, vêm atingindo em cheio certos privilégios masculinos, quer centrando sua ação no apoio estratégico à organização de entidades civis que se estruturam em torno de masculinidades subalternas (homossexuais, travestis, etc.), quer divulgando o fato de serem os homens os mais refratários a mudanças de comportamento no sentido de evitar ou prevenir tais males. Se isso é verdade, a ação do Estado moderno não deveria ser pensada como homogênea e fundamentalmente voltada para manutenção de uma genérica hegemonia masculina, como uma postura mais romântica poderia preferir. Conforme apontam sociólogos como Norbert Elias e historiadores como Robert Nye, a relação que envolve os homens (ou o poder masculino) e o Estado moderno configura-se muito mais como uma já secular queda-de-braço.

Enfim, o texto de Schraiber, Gomes e Couto mostra muito bem o modo como os homens emergem na pauta da Saúde Coletiva e trazem informações fundamentais para quem deseje desenvolver uma reflexão sobre o significado social e político de tal emergência. Mais importante, nele, os autores procuram compreender como as hierarquias de gênero configuram padrões específicos de cuidados de si, de adoecimento e mortalidade. Assim, vinculando sempre a reflexão sobre masculinidade às discussões mais amplas sobre as relações entre gênero e saúde, evitam uma abordagem vitimária, demonstrando que, quando se discute masculinidade e saúde, não se trata apenas da saúde dos homens, mas, através dela, da saúde de todos.

\section{Gênero, saúde dos homens e masculinidades}

Gender, men health and manliness

\section{Wilza Villela 7}

Qual não foi a minha honra ao receber o convite para dialogar com Lília, Romeu e Márcia sobre o artigo "Homens na pauta da Saúde Coletiva”! E qual não foi o meu prazer ao ler o trabalho, sistematização extensa e rigorosa dos caminhos pelos quais os homens estão entrando na pauta da saúde coletiva!

\footnotetext{
7 Instituto de Saúde, SES/SP. wilzavi@isaude.sp.gov.br
} 
Tem como pressuposto a dimensão social do processo saúde-doença, que considera o modo como os sujeitos circulam na sociedade fator determinante dos agravos à sua saúde, e a maneira que os sentidos e significados que o adoecimento adquire para cada um; os recursos disponíveis para o enfrentamento desse processo também estão relacionados aos contextos nos quais os sujeitos se situam. Ao tomar gênero como o conjunto de dispositivos culturais que transformam corpos com pênis ou com vulva em homem ou mulheres, marcando os corpos como masculinos ou femininos não apenas na sua anátomo-fisiologia, mas na constituição das suas identidades e na sua circulação social, é assumido o inexorável imbricamento do gênero no processo de adoecer.

A relação entre algumas marcas de gênero e certos agravos à saúde aparece, por exemplo, na reflexão sobre o exercício da sexualidade masculina, em que a disseminação do HIV entre mulheres e, posteriormente, entre homens que se identificavam como heterossexuais, ilustrou de modo dramático uma das conseqüências da norma socialmente imposta aos homens e aceita pela sociedade em geral, da prática sexual intensa, múltipla e variada, como atestado de "virilidade". A epidemia de Aids também explicitou que estas múltiplas parcerias podiam se dar com corpos masculinos ou femininos, independente de o homem se identificar como "homem" e heterossexual, o que ressalta a complexa relação que existe entre as idéias de "homens", "masculinidades" e as práticas sexuais. Complexidade que serve, dentre outras coisas, para alertar o profissional de saúde que a investigação sobre a forma de obter prazer sexual deve constar das anamneses clínicas, independente do modo como a pessoa se identifica ou do que a sua performance corporal sugere. De fato, como Parker (1989) já havia demonstrado, na cultura brasileira masculinidade e feminilidade, do ponto de vista sexual, têm mais a ver com a posição assumida no ato - ativo/passivo, penetrante/penetrado, do que exatamente com os corpos em atuação, o que faria com que homens se sentissem mais "homens" quanto mais corpos conseguisse penetrar, sejam corpos de homens ou de mulheres. Ao mesmo tempo, é sabido, especialmente pelo relato de profissionais do sexo, sejam mulheres ou travestis, que muitos homens gostam de serem penetrados sem que isso os faça sentirem-se gays, desde que a penetração seja feita por alguém identificado como "mulher". Ou seja, em contraste com os dados da pesquisa de Parker, estes relatos sugerem que, para alguns homens, o que conta para afirmação de sua identidade heterossexual é a aparência do objeto, mais do que a prática sexual propriamente dita. Isto nos faz pensar que o atributo de "atividade" como privilégio da sexualidade masculina, teria tanto a ver com prática quanto com a atitude em relação ao sexo, ativamente usufruído por meio de compra ou sedução.

Para além da epidemia de Aids, a crescente visibilidade de gays, lésbicas, transexuais e travestis tem trazido demandas específicas de saúde aos sistemas e serviços. São reivindicados espaços para atendimento de gays que contem com profissionais versados em questões de saúde sexual de homens que fazem sexo com homens e também em saúde mental, para os ajudar a lidar melhor com o preconceito, a estigmatização e a violência de que são vítimas, bem como a ampliação do acesso à cirurgia de readequação sexual, incluindo o tratamento prévio com hormônios e silicone. Estas demandas não apenas ajudam a aprofundar as diretrizes do SUS de universalidade e eqüidade, como também estimulam a crítica ao caráter binário que se atribui ao gênero, e reforçam a proposição de que gênero e sexualidade se constituem em esferas distintas da experiência humana, e que sua conexão se dá de modo diverso, quer se trate de homens ou de mulheres, em função do papel que cada um exerce na reprodução.

Para as mulheres a identidade de gênero (= sentir-se mulher e ser percebida como) esteve, e talvez ainda esteja, estreitamente relacionada ao exercício da maternidade. A equação "sexo = maternidade", verdadeira até a segunda metade do último século, operou como freio para o exercício da sexualidade pelas mulheres, facilitando a constituição de uma identidade de gênero calcada na sua possibilidade de controlar os desejos, dentre os quais o de sexo. O mesmo não teria ocorrido com homens, para quem a identidade estaria mais marcada pela não contenção ou mesmo exacerbação, entendida como sinal de poder. Os homens podem (e devem) satisfazer seus desejos, não sendo esperado de um homem o comedimento, seja sexual seja na alimentação, no uso de substâncias, na exposição a riscos, nas expressões de agressividade ou mesmo nas ações que visam ganhar/acumular dinheiro ou poder, atributo de masculinidade relacionado a um conjunto amplo de agravos a saúde, como o texto bem enfatiza.

Assim temos, grosso modo, que para as mulheres, uma identidade de gênero construída a 
partir de um ideal de maternidade determinaria o exercício da sua sexualidade. Para os homens, o exercício sem contenção da sua sexualidade determinaria a sua identidade de gênero, sendo o gênero a estrutura social que daria suporte a estes mecanismos identitários e de atuação. Isto coloca os gays, que embora tenham uma identidade de gênero específica, a exercerem sua sexualidade de modo tão livre como qualquer outro homem, como mais um dos sujeitos a serem considerados quando se vai refletir sobre o tema "masculinidades". Dito de outra forma, a condição para que um sujeito se identifique como gay é ter uma identidade biológica e de gênero - masculina, ao menos inicialmente. O que nos obriga considerar as práticas e necessidades dos homens gays em relação ao seu corpo e à saúde se queremos compreender, propositivamente, a questão "homens e saúde." Quais as conseqüências para a saúde da estetização e erotização pública do corpo masculino, trazido para a mídia por homens gays e hoje já generalizada? Existiriam diferenças qualitativas entre o desejado "cuidado de si", e o fisiculturismo, que recentemente, inclusive, provocou até a morte de jovens adolescentes no interior do País? A demanda atual para que os homens "cuidem mais da sua saúde" corresponderia à crescente redução do trabalho de cuidar tradicionalmente exercido por mulheres no âmbito doméstico? Qual o limite entre a tentativa de levar os homens aos serviços de saúde e a medicalização dos seus corpos, fenômeno vivenciado e denunciado pelas mulheres, em especial entre as décadas de 1970 e 1980? E até que ponto a explosiva venda do Viagra, e seus similares não seria mais um atestado de que os homens não admitem limites ao exercício da sua masculinidade?

Tem surgido na literatura feminista questionamentos em relação às perspectivas que tomam o gênero a partir de uma dimensão binária, heterossexual e oposicional, sem levar em conta os diferentes modos como cada sujeito vive a sua "masculinidade" ou "feminilidade". Como afirma Judith Butler (2003), se consideramos as hierarquias sociais que se constituem entre os diferentes homens e as diferentes mulheres, poderíamos dizer que o oposto da feminilidade não seria necessariamente a masculinidade, mas a falta de feminilidade. A autora pondera que o gênero atuaria tanto pela oposição binária masculino $\mathrm{x}$ feminino quanto por uma hierarquização entre as pessoas em termos das suas supostas performances sexuais. Haveria, por exemplo, uma tendência a considerarmos um homem jovem e saudável "mais homem " que um idoso portador de uma deficiência física ou mental. Em contrapartida, há alguns contextos que consideram os homens negros "mais homens", pela sua suposta maior virilidade. Ou seja, a idéia subjacente é que, embora o gênero tenha sido, e continue sendo, um poderoso instrumento analítico para se pensar os "modos de andar a vida" de homens e mulheres, é necessário analisar a fundo a utilização desta categoria, de modo a compreender melhor a articulação dinâmica do gênero e classe social, etnia e sexualidade na determinação das identidades, das subjetividades, dos riscos e das proteções à vida e à saúde que permeiam o cotidiano de cada um.

Connell (1995), por exemplo, sugere que pensemos as masculinidades em função dos jogos de poder que se estabelecem entre os homens em função de determinantes sociais intra gênero, como classe social e etnia, por exemplo. Seguindo esta perspectiva, Batista (2000) tem mostrado diferenciais de mortalidade entre homens brancos e negros, quando se consideram algumas causas, como Aids, doenças mentais (incluindo o alcoolismo), homicídios e outras, aventando a hipótese de que a facilidade maior com que homens negros e jovens, pobres e de baixa escolaridade, se envolvem em episódios de violência, ou abusam do álcool, poderia estar relacionada a uma tentativa imaginária de compensar a sua dificuldade em cumprir alguns dos ditames da masculinidade - poder, provimento - através da exacerbação de outros, como a força, a resistência e a coragem.

Há ainda que se ressalvar a necessidade de um melhor entendimento das relações entre masculinidade(s) e machismo. A princípio, o machismo seria uma atitude particular que homens e mulheres podem ter em relação a homens e mulheres, estando a masculinidade relacionada aos modelos de constituição de identidade dos homens. Embora existam conexões entre o machismo e a(s) masculinidade(s), o comportamento machista não decorre necessariamente da masculinidade, embora seja uma das possibilidades de vivência do masculino. Esta é uma demarcação importante a fazer, pois algumas vezes o machismo pode também ser um comportamento reativo à percepção de fragilidade ou insuficiência de cumprimento dos ideais de masculinidade e, em muitos dos agravos à saúde hoje identificados com os homens, em especial a violência doméstica e sexual, há que se reconhecer mais os traços do machismo do que, exatamente, da masculinidade. 
A perspectiva de que haveria um ideal de masculinidade ou de feminilidade é correlata com a de gênero como uma estrutura de poder, que atua indistintamente, mesmo que de modos diversos, sobre homens e mulheres. E, se é impossível alguém participar da cultura fora dos limites do gênero, parece também que este aponta para uma idealização de homens e mulheres que, sendo difícil de ser cumprida na prática, pode se transformar em sintoma ou agravo à saúde.

O artigo de Schraiber, Gomes e Couto, bem como parte significativa dos textos que lhe servem de referência partem da teorização elaborada pelo feminismo sobre gênero para refletir sobre a questão homens e saúde. Há que se reconhecer que a migração (ou expansão) da categoria gênero do espaço da luta política feminista para a academia e, nesta, para a reflexão/ ação no campo da saúde não se fez de modo simples ou linear, sendo até hoje objeto de disputa e debate pelos diferentes atores envolvidos. Uns apontam para a crescente despolitização da categoria ao ser apropriada pela academia. $\mathrm{Ou}$ tros ponderam que, tendo sido gênero cunhado para dar conta da opressão das mulheres, sua aplicabilidade na reflexão sobre homens e masculinidades deveria ser feita com cautela sob pena de reduzir a potencialidade explicativa da categoria ou, o que seria pior, falsear - por simplificação - as complexas relações e jogos de poder que os humanos estabelecem entre si, quando da vida em sociedade. Nesta polaridade colocam-se aqueles que postulam que a discussão de gênero e saúde atinge os homens quando do reconhecimento que, sem a sua participação e envolvimento, não seriam atingidas as metas demográficas estabelecidas para os países mais pobres nas Conferências Internacionais de População. Outros dizem que aventar o gênero para pensar as questões de violência é um modo de eludir um conjunto de outros fatores - políticos, econômicos e sociais - envolvidos na produção da violência, como o tráfico de armas, de drogas, a indústria da guerra e outros.

É evidente que o modo como os homens constroem e vivenciam as suas masculinidades está relacionado aos seus modos particulares de adoecer e morrer. No entanto, como tentamos apontar, este modo de construir e vivenciar a masculinidade é múltiplo e variável, bem como suas mediações com o processo saúde doença.

O necessário aprofundamento da abordagem das conexões entre gênero e saúde ganha um importante estímulo com a publicação de um trabalho tão completo e instigante quanto este que tive o prazer de comentar. Parabéns aos autores!

\section{Referências bibliográficas}

Butler 2002. Como os corpos se tornam matérias. Entrevista a Prins, Baukie e Meijer. Revista de Estudos Feministas 10(1).

Connell R 1995. Masculinities. University of California, Berkeley.

Parker R 1991. Corpos, prazeres, paixões. Best Seller, São Paulo.

\section{Os autores respondem}

The authors reply

\section{Saúde do homem:}

\section{uma abordagem em construção}

Health's man:

an approach in construction

O nosso debate e as opiniões dos nossos debatedores apontam para uma abordagem em construção acerca da saúde do homem. Ao tratarmos de tal temática, objetivávamos trazer um panorama de questões. Tal intenção, de início, nos impunha um limite: lidar com questões tão complexas que cada uma em si poderia ser objeto de uma discussão. No entanto, também tínhamos a certeza de que, com a participação de estudiosos no assunto, esse limite poderia ser atenuado. Os textos de Daniela Riva Knaut/ Paula Sandrine Machado, Estela Maria Leão de Aquino, Maria Cecília de Souza Minayo, Pedro Nascimento, Sérgio Carrara e Wilza Vilella, indo na direção do que havíamos pensado, não só ampliaram a nossa discussão como também trouxeram novas perspectivas sobre o assunto. A rica contribuição desses debatedores também nos possibilitou refletir sobre posicionamentos, conceitos e, sobretudo, incorporar idéias para melhor situar a discussão.

Uma importante questão é trazida por Estela Aquino e que se manifesta como preocupação de muitos pesquisadores que estudam a saúde da mulher no referencial de gênero: a visão essencialista de homens e mulheres em que podemos incorrer desde a tomada do objeto de estudo. Ao tomarmos a saúde da mulher e a saúde do homem em separado, tal abordagem pode, 